\title{
Aktivitas Olahraga Tradisional pada Kalangan Remaja di Masa Pandemi COVID-19
}

\section{Traditional Sports Activities among Adolescents during the Covid-19 Pandemic}

\author{
Ali Budiman \\ Program studi PJKR, STKIP Pasundan, Jalan Permana No. 32B Kota Cimahi, Jawa Barat, \\ 40553, Indonesia
}

\begin{abstract}
Abstrak
Penelitian ini bertujuan untuk mengetahui sejauhmana aktivitas olahraga tradisional di kalangan remaja pada saat masa Pandemic Covid-19. Untuk mendukung penelitian, metode penelitian survey kuantitatif dilakukan kepada 276 orang siswa Sekolah Menengah Atas di Jawa Barat, yang terdiri dari 146 laki-laki dan 130 perempuan. Instrumen angket disebarkan melalui aplikasi google form untuk memperoleh data penelitian. Data diolah menggunakan descriptive statistics with crossstabulation pada aplikasi SPSS versi 25. Hasil penelitian ini menunjukkan bahwa hanya 23\% remaja melakukan aktivitas permainan tradisional saat masa Pandemic Covid-19. Hal ini disebabkan karena modernisasi, globalisasi, serta situasi Pandemic Covid-19 yang terjadi saat ini sehingga berimbas pada fenomena aktivitas remaja saat ini.
\end{abstract}

Kata kunci: Olahraga Tradisional, Masa Pandemi Covid-19, Remaja.

\begin{abstract}
This study aims to determine the extent of traditional sports activities among adolescents during the Covid-19 Pandemic. To support the research, a quantitative survey research method was carried out on 276 high school students in West Java, consisting of 146 boys and 130 girls. The questionnaire instrument was distributed through the google form application to obtain research data. The data is processed using descriptive statistics with a crosstabulation on the SPSS version 25 application. The results of this study indicate that only $23 \%$ of adolescents engaged in traditional game activities during the Covid-19 Pandemic. This is due to the current modernization, globalization and Pandemic Covid-19 situation that have an impact on the current phenomenon of adolescents activity.
\end{abstract}

Keywords: traditional sports, Covid-19 Pandemic, Adolescents. 


\section{PENDAHULUAN}

Olahraga tradisional merupakan salah satu warisan nenek moyang yang menjadi ciri khas dari suatu daerah itu sendiri, selain daripada kesenian, makanan, bahasa, dan lain sebagainya. Maka dari itu layaknya kebudayaan nasional lainnya, olahraga tradisional juga merupakan asset penting yang harus selalu dijaga dan dilestarikan keberadaannya agar tetap dikenal dan selalu eksis di era modernisasi dan globalisasi saat ini. Di era modern saat ini globalisasi tidak hanya terjadi pada sector ekonomi maupun teknologi saja, melainkan globalisasi juga terjadi pada sector olahraga (Chatzigianni, 2018). Olahraga-olahraga global seperti olahraga yang merupakan budaya dari Amerika dan Negara-negara barat seolah dipaksakan pada Negara lain dengan mengorbankan budaya domestic mereka sendiri (Ueda, 2017). Hal ini juga terjadi di Negara Indonesia yang kaya akan keanekaragaman suku dan budaya.

Sejatinya globalisasi memang dapat memberikan hal-hal yang sangat positif, namun juga dapat memberikan dampak yang negative. Semakin terkenal dan maraknya olahraga global atau olahraga modern maka akan berdampak terhadap terasingkannya olahraga tradisional. Olahraga seperti sepakbola, bola basket, bola voli, atau bahkan esport jauh lebih dikenal dan popular dari pada olahraga tradisional di kalangan masyarakat terlebih kalangan remaja dan anak-anak yang memang terlahir pada zaman modern. Padahal tidak bisa dipungkiri bahw a olahraga tradisional juga memiliki berbagai manfaat yang sama dengan olahraga konvensional/modern pada umumnya. Salah satu manaat dari olahraga tradisional adalah berdampak baik terhadap perkembangan motoric (Pic et al., 2019).

Akan tetapi, hal yang lebih mengkhawatirkan adalah terjadinya pergeserak aktivitas remaja di era modern saat ini. Tingkat aktivitas fisik kaum muda semakin berkurang ketika mereka memasuki masa remaja (Inchley \& Currie, 2016). Kalangan remaja cenderung lebih memilih bermain game dan bersosial media atau memainkan gadget untuk mengisi waktu luang mereka (Khlomov et al., 2018). Sehingga jangankan untuk bermain olahraga tradisional, untuk beraktivitas fisik dan bersosialisasi di lingkungannya pun jarang dilakukan. Terlebih di masa Pandemi Covid-19 seperti sekarang ini. Yang mana kita ketahui untuk kegiatan bersosialisasi dan aktivitas yang erat dengan kerumunan sangatlah dibatasi.

Maka dari itu penelitian ini bertujuan untuk mengetahui apakah di era modern seperti sekarang ini aktivitas olahraga tradisional tetap dilaksanakan oleh kaum remaja, terlebih lagi di masa pandemic Covid-19 saat ini. 


\section{METODE}

Metode penelitian yang digunakan dalam penelitian ini adalah metode survey kuantitatif. Populasi penelitian yang digunakan dalam penelitian adalah siswa-siswi Sekolah Menengah Atas di Jawa Barat. Teknik convenience sampling digunakan untuk menentukan sampel yang akan digunakan dalam penelitian, sehingga terpilih sebanyak 276 siswa, yang terdiri dari 146 laki-laki dan 130 perempuan yang bersedia terlibat dalam penelitian. Instrumen penelitan yang digunakan adalah kuesioner mengenai kegiatan aktivitas olahraga tradisional yang dilakukan dengan skala Guttman. instrument tersebut disebarkan menggunakan aplikasi google form sepanjang bulan Januari hingga Maret 2021. Semua data dianalisis menggunakan perhitungan statistik penelitian kuantitatif dari Statistical Package for the Social Science (SPSS 23.0). Deskriptif statistics dengan crosstabulation digunakan untuk mengungkap masalah dalam penelitian ini.

\section{HASIL DAN PEMBAHASAN}

\section{Hasil}

Data hasil penyebaran quesioner dihitung menggunakan Deskriptif statistics dengan crosstabulation yang menunjukkan hanya sebanyak $23 \%$ remaja melakukan aktivitas olahraga tradisional di masa pandemi. Table 1 di bawah ini menjelaskan hasil perhitungannya:

Tabel 1. Persentase aktivitas olahraga tradisional di kalangan remaja gender * aktivitas olahraga tradisional Crosstabulation

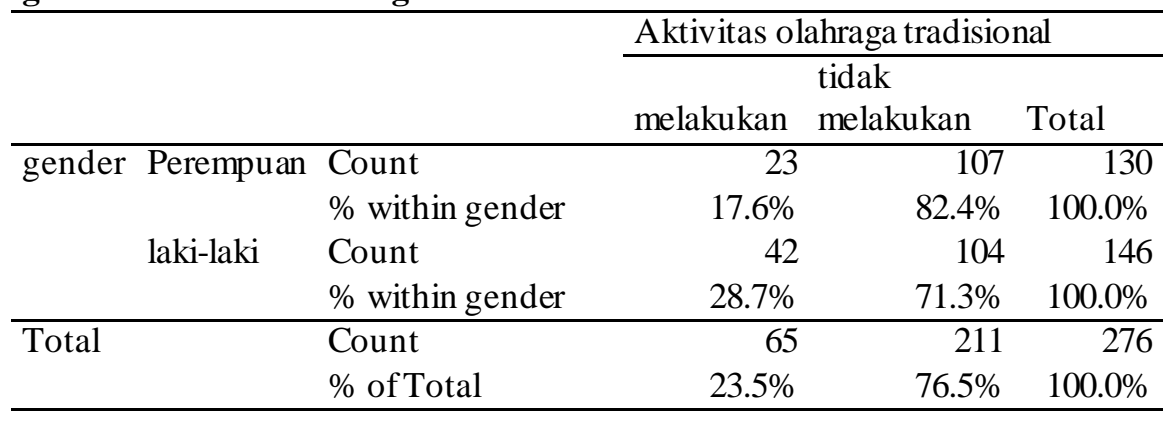

Pada table 1 menunjukkan bahwa sebanyak 65 orang remaja yang terdiri dari 23 remaja perempuan dan 42 remaja laki-laki atau setara dengan $23.5 \%$ melakukan aktivitas permainan olahraga tradisional, sedangkan sisanya yaitu 211 orang remaja yang terdiri dari 107 remaja perempuan dan 104 remaja laki-laki tidak melakukan aktivitas olahraga tradisional. 
Selanjutnya table 2 di bawah ini akan memperlihatkan bagaimana sebaran tanggapan sampel penelitian berdasarkan letak demografis tempat tinggal mereka (perkotaan atau perdesaan).

Tabel 2. Persentase aktivitas olahraga tradisional di kalangan remaja berdasarkan demografis

demografis * aktivitas olahraga tradisional Crosstabulation

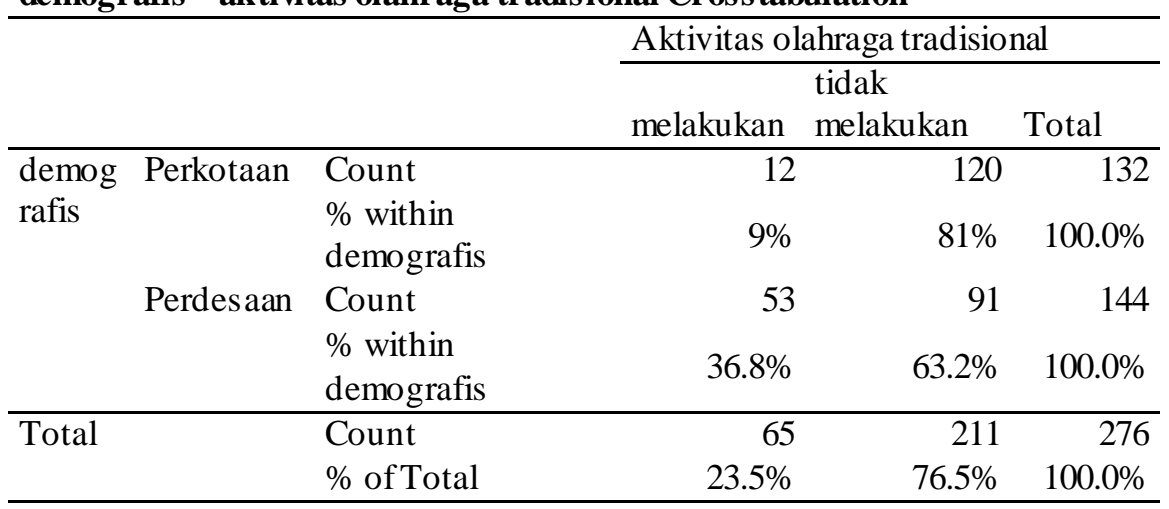

Pada table 2 di atas menunjukkan bahwa sebanyak 12 orang remaja di perkotaan atau 9\% remaja perkotaan melakukan aktivitas olahraga tradisional, dan sebanyak 120 orang remaja atau berkisar $81 \%$ remaja perkotaan tidak melakukan aktivitas olahraga tradisional. Tabel 2 juga mengemukakan bahwa sebanyak 53 orrang remaja atau $36.8 \%$ remaja di perdesaan melakukan aktivitas olahraga tradisional dan sebanyak 91 orang atau 63.2\% remaja di perdesaan tidak melakukan aktivitas olahraga tradisional.

Diagram di baw ah ini akan memaparkan persentase jenis olahraga tradisional apa saja yang kalangan remaja lakukan di masa pandemic Covid-19 saat ini.

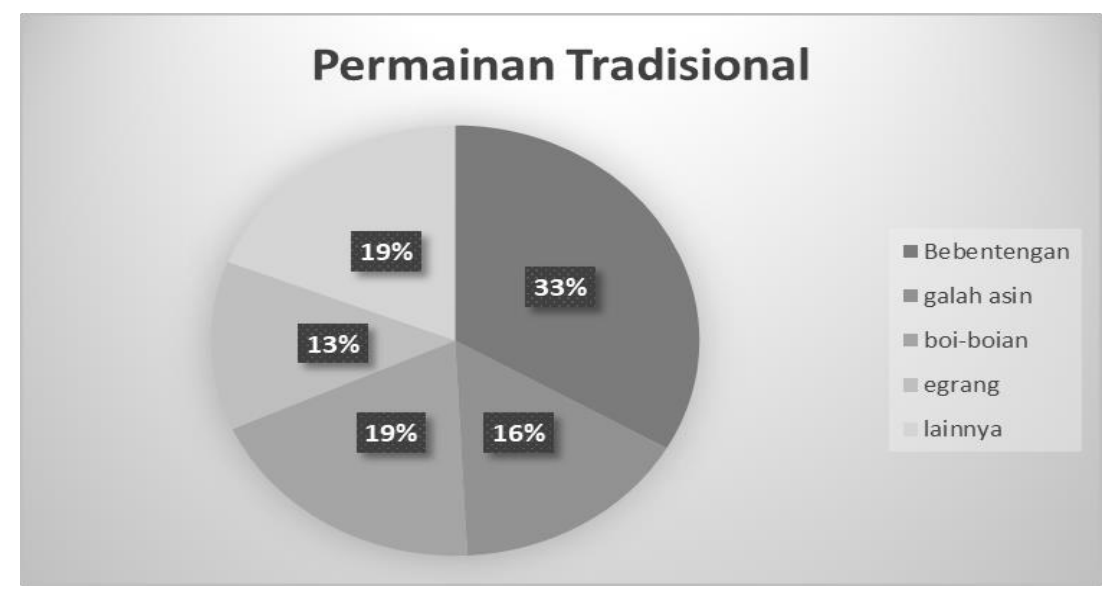

\section{Gambar 1. Diagram jenis permainan tradisional yang dilakukan}

Berdasarkan gambar di atas dapat diketahui bahwa 33\% atau sebanyak 21 orang remaja melakukan jenis olahraga tradisional bebentengan, sebesar $16 \%$ atau sebanyak 10 orang remaja melakukan jenis olahraga tradisional galah asin, sebesar 19\% atau sebanyak 12 orang remaja melakukan jenis olahraga tradisional boi-boian, sebesar $13 \%$ atau 8 
orang remaja melakukan jenis olahraga tradisional egrang, dan sebesar 19\% atau sebanyak 12 orang remaja melakukan jenis olahraga tradisional yang lainnya.

\section{Pembahasan}

Penelitian sebelumnya mengungkapkan bahwa budaya domestic dalam hal ini olahraga tradisional semakin tersisih dengan datangnya budaya olahraga global seperti olahraga-olahraga dari barat dan amerika (Ueda, 2017). Factor modernisasi dan globalisasi berdampak penting terhadap terjadinya situasi tersebut. Olahraga tradisional seolah semakin meredup ditengah populernya olahraga global seperti sepakbola, bola basket, bola voli, atau bahkan e-sport dan sebagainya, terlebih di kalangan remaja dan di masa pandemic Covid-19 saat ini. Hasil penelitian ini memperlihatkan bahwa hanya berkisar 23,5\% remaja melakukan aktivitas olahraga tradisional di masa pandemic Covid19.

Remaja laki-laki lebih sering melakukan aktivitas olahraga tradisional yaitu sebesar $28,7 \%$ dibandingkan dengan remaja perempuan yang hanya $17,6 \%$ saja yang melakukan aktivitas olahraga tradisional (lihat table 1). Hal tersebut bukan tanpa berdasar, karena pada dasarnya tingkat ketertarikan remaja perempuan pada bentuk aktivitas fisik lebih rendah dibandingkan deng an laki-laki (Chalabaev et al., 2013; Lissitsa et al., 2010; Wheatley et al., 2020). Sehingga tidak mengeherankan apabila remaja laki-laki lebih sering melakukan olahraga tradisional yang penuh dengan aktivitas fisik di dalamnya dibandingkan dengan remaja perempuan.

Selanjutnya hasil penelitian ini juga mengemukakan bahwa lebih banyak remaja di perdesaan yang melakukan aktivitas olahraga tradisional dibandingkan dengan kalangan remaja yang tinggal di lingkungan perkotaan (lihat table 2). Bukan tanpa alasan, penelitian menyebutkan bahwa tingkat atau kegiatan aktivitas fisik masyarakat di pedesaan lebih baik dari pada kegiatan aktivitas fisik mas yarakat yang berada di daerah perkotaan (Dicaraka \& Susiana Candrawati, 2010, Saras wati \& Dieny, 2012). Di samping itu, masyarakat di pedesaan masih banyak dan bahkan lebih mengenal budaya tradisional dibandingkan dengan masyarakat di perkotaan yang memungkinkan aktivitas olahraga tradisional di perkotaan lebih jarang dilakukan dibandingkan dengan dipedesaan (Kuntardi, 2021). Aspek lainnyadengan lekatnya kebudayaan di mas yarakat pedesaan, seperti pelaksanaan upacara adat, kegiatan gotong royong, dan sosialisasi yang tinggi lebih memungkinkan masyarakat pedesaan tersebut sedikit abai terhadap protocol ke sehatan dibanding dengan mas yarakat di perkotaan (Kuntardi, 2021). Selain itu ketesediaan sarana seperti lapanganbermain di daerah pedesaan yang lebih luas dan lebih banyak tersedia dibandingkan dengan di perkotaan yang mana lahan seperti lapangan bermain semakin sedikit, memungkinkan aktivitas olahraga tradisional di pedesaan lebih banyak dilakukan dis ban ding dengan diperkotaan (Borgers et al., 2016; Vos \& Scheerder, 2014). 
Penelitian ini juga mengemukakan bahwa di antara 65 orang remaja yang melakukan aktivitas olahraga tradisional di mas a pandemic Covid-19 diantaranya sebanyak 21 orang remaja melakukan jenis olahraga tradisional bebentengan sebanyak 10 orang remaja melakukan jenis olahraga tradisional galah asin, sebanyak 12 orang remaja melakukan jenis olahraga tradisional boi-boian 8 orang remaja melakukan jenis olahraga tradisional egrang, dan sebanyak 12 orang remaja melakukan jenis olahraga tradisional yang lainnya. Aktivitas olahraga tradisional bebentengan lebih banyak digandrungi remaja pada saat ini dikarenakan jenis olahaga tradisional ini mungkin lebih mereka kenal dan sering mereka laksanakan pada pembelajaran PJOK di sekolah ketika pemanasan maupun pada saat materi olahraga tradisional.

Secara keseluruhan, rendahnya aktivitas olahraga tradisional di kalangan remaja bukanlah tidak berdasar mengingat di era modern saat ini banyak remaja lebih memilih untuk melakukan aktivitas seperti bermain game dan social media di gadget sebagai sarana rekreasi mereka (Eklund \& Roman, 2019; Khlomov et al., 2018). Hal tersebut mempengaruhi perubahan dan budayaterutama dalamhal kegiatan waktu s enggang dibeberapa decade terakhirini (Seippela et al., 2010; Vollmer et al., 2019).

Padahal olahraga tradisional adalah budaya dan kekayaan yang menggambarkan komponen ideologis suatu bangsa (Ho, 2013) yang harus dilestarikan, selain itu olahraga tradisional jug a memberikan berbagai manfaat yang sangat penting dimana aktivitas fisik melalui olahraga tradisional dapat mengembangkan kemampuan motoric (Pic et al., 2019; Satriana, 2013) dan juga pendapatkan pengalaman yang bermakna (Lavega et al., 2018).

Semakin menurunnya tingkat aktivitas remaja dalam melakukan olahraga tradisional perlu mendapatkan perhatian khusus dari pemerintah maupun kalangan organisasiyang menaungi olahraga tradisional. Berbagai upaya seperti mengadakan event untuk mengenalkan dan memasy arakatkan olahraga tradisional pada mas yarakat yang dapat men arik animo dan partisipasi mas yarakat yang tinggi (Chalip et al., 2017, 2017; Lipoński, 2017) perlu diadakan secara berkala dan diberbagai tempat, serta upaya s trategi 'kunci' lain sepertimemanfaatkan media dan sekolah (Xu, 2018) untuk turut mempromosikan olahraga tradisional.

\section{KESIMPULAN}

Melihat hasil penelitian di atas, penulis dapat mengambil keimpulan bahwa aktivitas olahraga tradisional khususnya di kalangan remaja sangatlah mengkhaw atirkan. Terlepas dari masa pandemic Covid-19 saat ini, aktivitas atau pengetahuan remaja akan olahraga tradisional harus tetap terjaga dan olahraga tradisional tersebut harus tetap dilestarikan baik itu dengan cara dipekenalkan dan disosialisasikan kembali oleh pihakpihak terkait. Sehingga di seiringnya kemajuan teknologi dan modernisasi pada setiap 
bidang saat ini, olahraga tradisional yang merupakan kekayaan dan budaya bangsa tetap terjaga dan tidak punah tergerus zaman.

\section{DAFTAR PUSTAKA}

Borgers, J., Vanreusel, B., Vos, S., Forsberg, P., \& Scheerder, J. (2016). Do light sport facilities foster sports participation? A case study on the use of bark running tracks. International Journal of Sport Policy, 8(2), 287-304. https://doi.org/10.1080/19406940.2015.1116458

Chalabaev, A., Sarrazin, P., Fontayne, P., Boiché, J., \& Clément-Guillotin, C. (2013). The influence of sex stereotypes and gender roles on participation and performance in sport and exercise: Review and future directions. Psychology of Sport and Exercise, 14(2), 136-144. https://doi.org/10.1016/j.psychsport.2012.10.005

Chalip, L., Green, B. C., Taks, M., \& Misener, L. (2017). Creating sport participation from sport events: making it happen. International Journal of Sport Policy, 9(2), 257-276. https://doi.org/10.1080/19406940.2016.1257496

Chatzigianni, E. (2018). Global sport governance: globalizing the globalized. Sport in Society, 21(9), 1454-1482. https://doi.org/10.1080/17430437.2017.1390566

Dicaraka, B. A., \& Susiana Candrawati, M. A. W. (2010). Perbedaan Tingkat Aktivitas Fisik Antara Remaja Desa dan Kota Di Kabupaten Banyumas. Mandala of Health, 7, 15-19.

Eklund, L., \& Roman, S. (2019). Digital Gaming and Young People's Friendships: A Mixed Methods Study of Time Use and Gaming in School. Young, 27(1), 32-47. https://doi.org/10.1177/1103308818754990

Ho, W. C. (2013). Behind the scenes of music education in China: a survey of historical memory. Discourse, 34(5), 673-688. https://doi.org/10.1080/01596306.2013.728363

Inchley, J., \& Currie, D. (2016). Growing up unequal: gender and socioeconomic differences in young people's health and well-being. Health Behaviour in Schoolaged Children (HBSC) study: international report from the 2013/2014 survey (Issue 7). World Health Organization.

Khlomov, K. D., Kondrashkin, A. V., Kuzin, P. A., Kalyakina, S. M., Tyulkanova, K. I., \& Medvedev, D. P. (2018). The Adolescent in the Online Game: Participant Observation and the Experience of Social Work. Russian Education and Society, 60(4), 315-333. https://doi.org/10.1080/10609393.2018.1473690

Kuntardi, D. V. S. (2021). Dinamika Sistem Sosial Masyarakat Pedesaan di Masa Pandemi Covid-19. Jurnal IDEAS, 7(1), 1-10. https://doi.org/10.32884/ideas.v

Lavega, P., Prat, Q., De Ocáriz, U. S., Serna, J., \& Muñoz-Arroyave, V. (2018). Aprendizaje basado en la reflexión sobre la acción a través de los juegos tradicionales. El caso de la pelota sentada. Cultura y Educacion, 30(1), 142-176. https://doi.org/10.1080/11356405.2017.1421302

Lipoński, W. (2017). Rattle running, dry wrestling, and boxing in ... opera, or regional sports and games in the historical and cultural tradition of eastern Europe. International Journal of the History of Sport, 34(10), 899-914. https://doi.org/10.1080/09523367.2017.1408587

Lissitsa, S., Galily, Y., \& Chachashvili-Bololotin, S. (2010). Talking or acting? Gender 
differences in physical activity participation in Israel at the threshold of the 21st century. European Journal for Sport and Society, 7(1), 31-40. https://doi.org/10.1080/16138171.2010.11687843

Pic, M., Lavega-Burgués, P., \& March-Llanes, J. (2019). Motor behaviour through traditional games. Educational Studies, 45(6), 742-755. https://doi.org/10.1080/03055698.2018.1516630

Saraswati, I., \& Dieny, F. F. (2012). Perbedaan Karakteristik Usia, Asupan Makanan, Aktivitas Fisik, Tingkat Sosial Ekonomi Dan Pengetahuan Gizi Pada Wanita Dewasa Dengan Kelebihan Berat Badan Antara Di Desa Dan Kota. Journal of Nutrition College, 1(1), 280-291. https://doi.org/10.14710/jnc.v1i1.726

Satriana, M. (2013). Permainan Tradisional Berbasis Budaya SundaSebagai Sarana Stimulasi Perkembangan Anak Usia Dini. Malpaleni Satriana, Volume 7, 65-84.

Seippela, Ø., Ibsen, B., \& Norberg, J. R. (2010). Introduction: Sport in scandinavian societies. Sport in Society, 13(4), 563-566. https://doi.org/10.1080/17430431003616167

Ueda, Y. (2017). Political economy and judo: the globalization of a traditional Japanese $\begin{array}{lllll}\text { sport. Sport in } & \text { Society, } & \text { 20(12), } & 1852-1860 .\end{array}$ https://doi.org/10.1080/17430437.2017.1232354

Vollmer, J., Lohmann, J., \& Giess-Stüber, P. (2019). Relevance of parental cultural capital for adolescents' physical exercise and sport activity. European Journal for Sport and Society, 16(4), 342-360. https://doi.org/10.1080/16138171.2019.1693146

Vos, S., \& Scheerder, J. (2014). Fact or fiction? An empirical analysis of cooperation between mass sport providers at the local level. European Journal for Sport and Society, 11(1), 7-34. https://doi.org/10.1080/16138171.2014.11687931

Wheatley, C., Johansen-Berg, H., Dawes, H., \& Davies, E. (2020). Perceptions of active and inactive prototypes are associated with objective measures of physical activity in adolescents. Psychology, Health and Medicine, 00(00), 1-12. https://doi.org/10.1080/13548506.2020.1738018

$\mathrm{Xu}$, S. (2018). Cultivating national identity with traditional culture: China's experiences and paradoxes. $\quad$ Discourse, 615-628. https://doi.org/10.1080/01596306.2017.1302410 